\title{
Comparative Study on Multistorey Building with And Without Floating Columns
}

\author{
Shubham Mandwale ${ }^{1}$, Nikhil Pitale ${ }^{2}$ \\ ${ }^{*}$ Student, G. H. Raisoni College of Engineering, Nagpur, Maharashtra, India \\ ${ }^{2}$ Assistant Professor, G. H. Raisoni College of Engineering, Nagpur, Maharashtra, India
}

\begin{abstract}
Modern construction techniques and good architectural views of building come with the concept of floating column. FC gives good architectural views to the structure also for the space requirement for parking or movements of vehicles floating column is delivered at the ground floor. Two models of six storey building structure with FC and structure with regular columns for the comparative study on the parameters such as flat displacement, storey drift, time period and base shear. RSA has been completed using ETABS 2016 software.
\end{abstract} Keywords : Floating column (FC), Response Spectrum Analysis (RSA), ETABS.

\section{INTRODUCTION}

This During the last few years, India's infrastructure system has grown up extremely also large numbers of research has been performed in construction area. Multistorey structures are created for industrial, residential and commercial purpose with open ground storey. The main problem is to get space for the parking, halls, reception lobbies. Based totally on the making plans of higher floors intently spaced columns aren't usable inside the lower floors, for the solution of problem concept of FC come in construction field. Vertical member of structure called column starting from base assignment the load to ground. Floating column is not different from the regular column but it's far rest on beam that's horizontal member. It moves a factor load on a beam and the burden transfer to the column underneath the beam. Floating column is use to satisfy the space requirement and for the better elevations of the building. Structure with floating columns designed for vertical loads i.e. gravity loads and this structure is harmless below vertical loads but this structure are not planned for the horizontal loads like seismic loading. In seismic prone locations this form of construction are insecure. Now a day's earthquake resistant layout got major interest in design of any form of structure.

\section{A. Floating Column}

Vertical member of structure called column which begins from the base of substructure i.e. foundation and transferals the load of to the earth. FC is also a vertical member which respites on the beam by its inferior end and actions point load on the beam, the load from beam. transferred to the close column that is below the beam as shown in fig 1 .

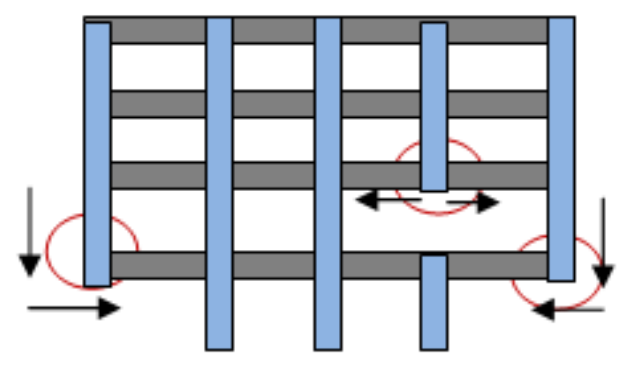

Figure 1.Floating column structure. 


\section{RESULTS II. LITERATURE REVIEWS}

Deshmukh [1], Observe On Seismic evaluation of Multistorey constructing With FC the use of Staad.ProV8i. From the study author concluded that FC structures in seismic active zones does no longer motive extra displacement and are secure for construction. Additionally these systems gives right aesthetic appearance than the non-floating column and uninterrupted space for showrooms, theaters etc.

Husain [2], Studied on "Seismic response of multistorey structure with floating and setback columns" From the analysis author concluded that building with discontinuity in column performed poorly under seismic excitation do not prefer to construct FC or setback column in buildings unless there is a proper purpose and functional requirement for those. With growth in dimensions of all individuals additionally it is getting more displacements than a ordinary buildings and also the cost production additionally extended if they are to be provided proper designing of structure is required.

Wasay [3], Studied on seismic effect on multi storey structure with different positioning of FC. From the study author determined that the resistance of soft storey with corner FC is minimum after compared to another types of models and is maximum in soft storey without FC. Hence, soft storey with corner floating column is not appropriate for earthquake prone areas.

Pradeep [4], RSA has done for the analysis. From the analysis author concluded that storey shear force is extreme at first storey and it diminished to a least in the top storey. Base shear is $25 \%$ larger in medium soil compare to hard soil. FC building has 35\% more displacement than the without FC building. Concluded that base shear is more in medium soil compared to firm soil in both cases. From response spectrum analysis concluded that FC at corner of exterior frame found critical than other locations.

\section{OBJECTIVE}

1.Equating the outcomes of normal building with FC building.

2.Finding the parameters storey displacements, storey shear, storey drift, time period for modeled structures under seismic excitation.

3.To determine which structure is superior to another in higher earthquake zone.

\section{METHODOLOGY}

The structure considered is ordinary six storey regular RC building of dimension of plan with $16 \mathrm{mX16m}$ and considered to be placed in zone V according to IS 1893-2016.

Modeling of the Building,

Two cases are considered

Case 1: RC structure without FC i.e., Normal $(G+5)$ storey building.

Case 2: RC structure with FC, columns eliminated in corner of exterior body.

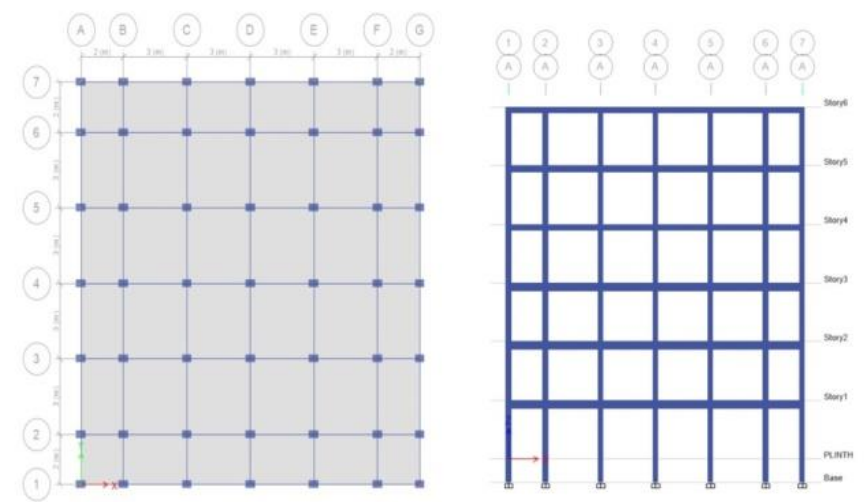

Figure 4.1: Plan and elevation of building without FC 


\subsection{Load Combinations:}
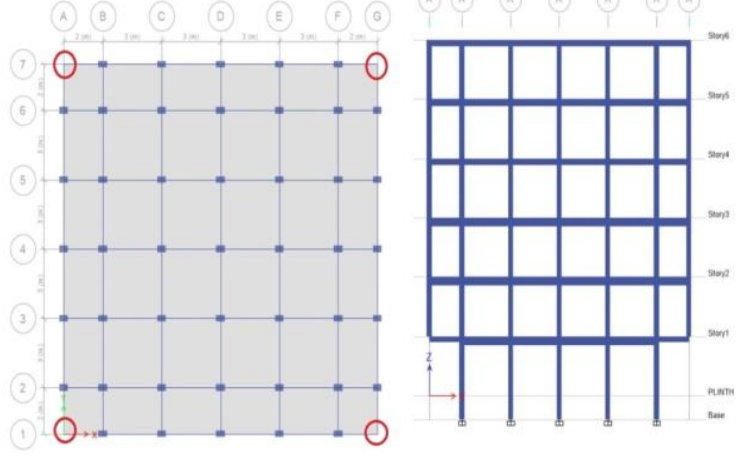

Figure 4.2 : Plan and elevation of building with floating column (FC provided at the corner of exterior frame)

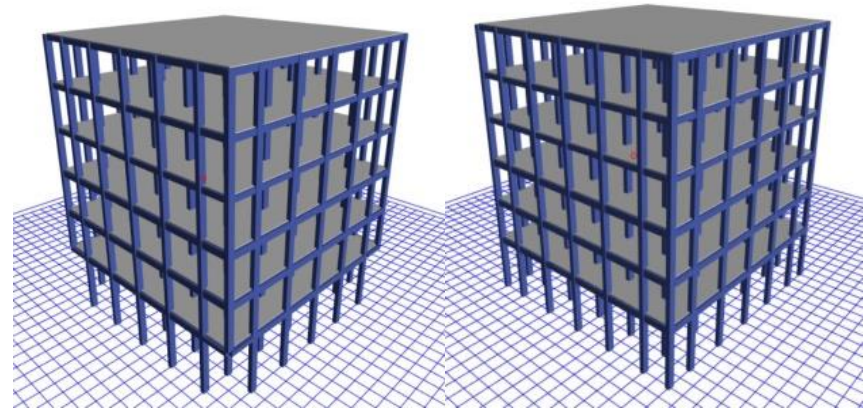

Figure 4.3 : 3D view of floating column and without FC structures

\section{A) Structure Data:}

\begin{tabular}{|c|c|c|}
\hline $\begin{array}{l}\text { SR. } \\
\text { NO }\end{array}$ & NAME & DISCREPTION \\
\hline 1 & AREA OF BUILDING & $16 \mathrm{M} \mathrm{X} 16 \mathrm{M}$ (256 SQ.M.) \\
\hline 2 & $\begin{array}{l}\text { GRADE OF } \\
\text { CONCRETE }\end{array}$ & M25 \\
\hline 3 & NO. OF FLOORS & $\mathrm{G}+5$ \\
\hline 4 & TOTAL HEIGHT & $18.28 \mathrm{M}$ \\
\hline 5 & STOREY HEIGHT & 3.048 \\
\hline 6 & BUILDING TYPE & RESIDENTIAL BUILDING \\
\hline & \multicolumn{2}{|c|}{ 7. LOADS } \\
\hline & $\begin{array}{l}\text { A) DEAD LOAD } \\
\text { (FRAME } \\
\text { LOAD) }\end{array}$ & $13 \mathrm{kN} / \mathrm{m}$ \\
\hline & B) LIVE LOAD & $2 \mathrm{kN} / \mathrm{m}^{2}$ \\
\hline & C) FLOOR FINISH & $1.5 \mathrm{kN} / \mathrm{m}^{2}$ \\
\hline 8. & \begin{tabular}{|l|} 
LOAD \\
COMBINATIONS
\end{tabular} & AS PER IS 456:2000. \\
\hline 9 . & WALL THICKNESS & $230 \mathrm{MM}$ \\
\hline 10 & BEAM SIZES & 230MMX350MM,300MMX450MM,300MMX500MM \\
\hline 1 & COLUMN SIZES & 300MMX450MM \\
\hline 12 & SLAB THICKNESS & $125 \mathrm{MM}$ \\
\hline
\end{tabular}

Table 1: Structure data
Load combinations used in analysis as per IS 456:2000.
1. 1.5(D.L.+ L.L)
2. 1.2(D.L.+ L.L $\pm \mathrm{EQX})$
3. 1.2(D.L.+ L.L $\pm \mathrm{EQY})$
4. 1.5(D.L. $\pm \mathrm{EQX})$
5. 1.5(D.L . $\pm \mathrm{EQY})$
6. (0.9D.L. + 1.2 L.L. \pm 1.2 EQX)
7. (0.9D.L. +1.2 L.L. \pm 1.2 EQY)

\section{RESULTS AND DISCUSSION}

\subsection{Storey Displacement}

The lateral movement of a constructing that's caused by the lateral pressure is referred to as storey displacement. With the institution of FC in a building, storey displacement rises.

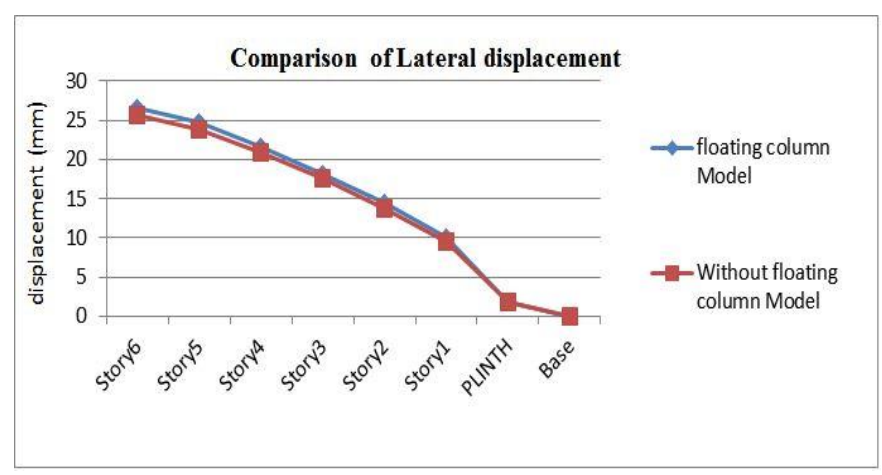

Figure 5.1: Comparison of lateral displacement

\subsection{Storey Drift}

Storey Drift is the variance among the relative storey displacements. Storey displacement is straight proportional to the storey drift. As we introduce FC in a building, storey drift rises as storey displacement rises. 


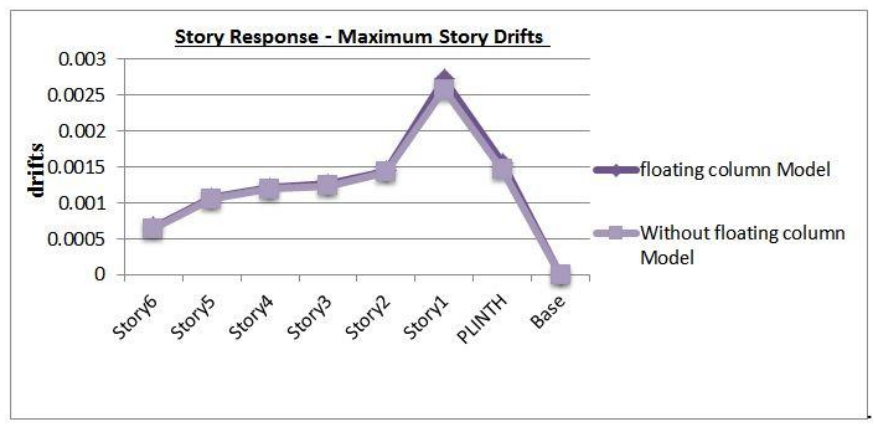

Figure 5.2: Comparison of storey drifts

\subsection{Storey Shear}

The forces which can be induced at each storey during earthquake are known as the storey forces. Storey forces induced in ordinary building will be more than building containing FC. For a building, storey forces goes on growing for decrease stories and it will likely be most for bottom storey.

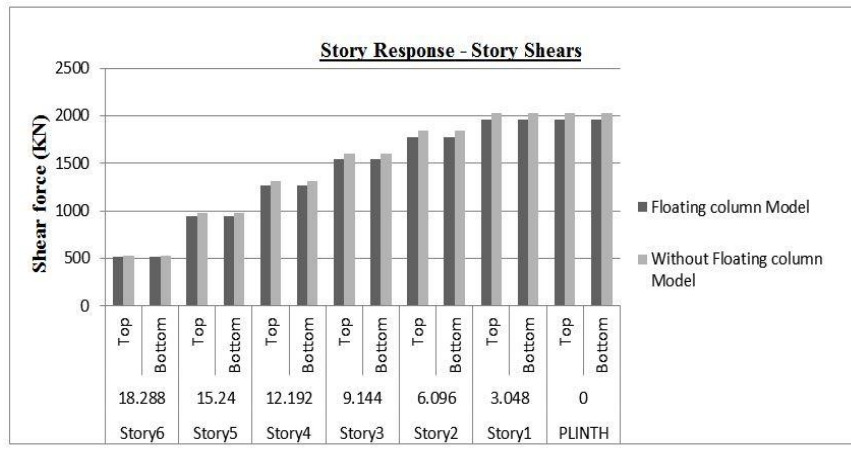

Figure 5.3: Comparison of storey shear

\subsection{Time Period}

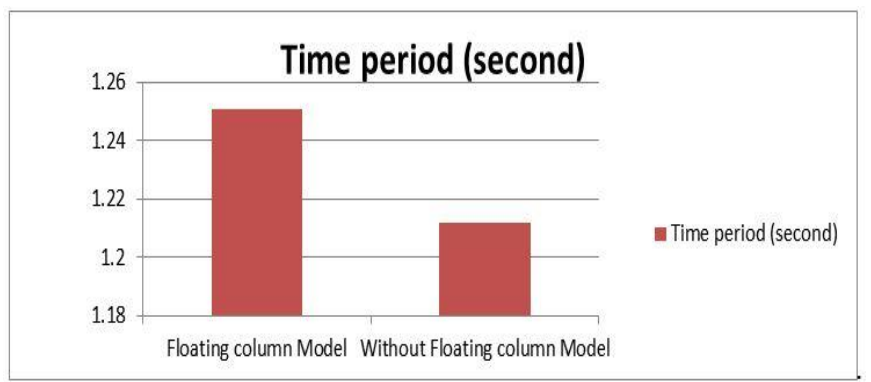

Figure 7: Time period for one cycle

\section{From the RSA following results obtained}

- Displacement- Displacement of structure rises with rise in height of structure. FC structure has more displacement compare to without FC structure.
- Storey drift- FC structure has more drift value equate to without FC structure.

- Storey shear- Storey shear value falls for FC structure compare to without FC structure.

- Time period- Time period for FC structure is more compare to without FC structure.

\section{CONCLUSIONS}

From the analysis above results shows variations for the different parameters like storey shear, storey drift, lateral displacement, base shear, time period of structure under earthquake excitation for the seismic zone V. FC structure provide extra open space, for the different architectural views it is useful but for the safety purpose in seismic prone area it is unfavorable and the risk of failure is extra.

\section{FUTURE SCOPE}

1. The present study reflects rigid floor diaphragm action only. In future same buildings could be studied considering flexible floor diaphragm.

2. In this work the outcome of torsion is not considered. In future building can be studied considering the torsion effect.

3. The present study is limited to about $G+5$ storied building with FC and without FC are compared in which checked by deflection, storey drifts, storey stiffness, and base shear.

So there is large scope for the future study in future:

a. The applicability of the procedure of taller structure and structure with large time period need to be investigated.

b. The frequency and twisting moment in column can be calculated for given models in both cases. 
c. To execute a static non-linear analysis and tested whether that plastic hinges will form at FC.

d. An experimental investigation and verification can be done with small scale model using shake table under simulated motions.

e. Design and estimation of building is necessary for checking the cost effectiveness of these measures used for upgrading performance of structure under seismic loading.

\section{REFERENCES}

\section{Codes}
A) IS 456:2000:
Plain And Reinforced
B) IS 800:2007:
Concrete
C) IS 1893(PART 1):2016:
General Construction In Steel
Criteria For Earthquake
Resistant Design Of
Structures

[1]. Prof. Y. R. Deshmukh, S. P. Jadhav, S. M. Shirsat, A. S. Bankar, D. G. Rupanawar (2018) "A Study On Seismic Analysis of Multistorey Building With Floating Column Using Staad.ProV8i”, International Journal of Engineering Research and Technology, Vol. 05, Issue 05, (ISSN: 2395-0056) .

[2]. Altaf Husain, Dr. Kailash Narayan, "Seismic Response of Multistory Building with Floating and Setback Columns", International Journal of Engineering Research in Mechanical and Civil Engineering, International Journal of Engineering Research in Mechanical and Civil Engineering, Vol. 03, Issue 05, (ISSN: 24561290).

[3]. Mohammed Abdul Wasay, Suraj Baraik, “ Seismic Effect on Multi Storey Building with Different Positioning Of Floating Column", International Journal of Innovative Technology

and Exploring Engineering (IJITEE), ISSN: 2278-3075, Volume-8 Issue-11, September 2019.

[4]. Pradeep D, Chethan V R, Ashwini B T, "Seismic Analysis Of Multi-Storey Building With Floating Columns Using Etabs", IJSDR, ISSN: 2455-2631,Volume-2, Issue-9, September 2017.

\section{Cite this article as :}

Shubham Mandwale, Nikhil Pitale, " Comparative Study on Multistorey Building with And Without Floating Columns", International Journal of Scientific Research in Science and Technology(IJSRST), Print ISSN : 2395-6011, Online ISSN : 2395-602X, Volume 7, Issue 3, pp.418-422, May-June-2020. Available at doi : https://doi.org/10.32628/IJSRST207387 Journal URL : http://ijsrst.com/IJSRST207387 